\title{
periferio
}

\section{DECLARAÇÃO DE AMOR GAY NO COLÉGIO: OS COMENTÁRIOS DE UMA POSTAGEM NO FACEBOOK}

\author{
Luciano Pereira dos Santos ${ }^{1}$ \\ Universidade Federal de Pelotas - UFPel
}

\section{Resumo}

Superando a necessidade de contato, proximidade física e temporal, as redes sociais, são lugares de encontro, de trocas, de exposição de si. Nesse sentido, o sujeito pós-moderno é atravessado pelas novas tecnologias da comunicação e pelos meios de comunicação de massa que influenciam sua constituição e se tornam lócus privilegiado de onde ele se expõe e se legitima. Fruto da globalização, estas novas práticas de interação social surgem como veículo de compartilhamento e descentralização de saberes, ao passo que, ao mesmo tempo sofrem o risco da legitimação de hegemonismos, servindo como veículo de propagação de crenças e preconceitos diante da diversidade cultural, do pluralismo e das singularidades ali expostas. 0 objetivo desse artigo é discutir as percepções relativas às homossexualidades presentes nas sociedades humanas contemporâneas a partir de uma breve análise dos comentários gerados pela postagem de um vídeo gravado por ocasião do pedido de namoro feito por um adolescente a outro garoto no pátio da escola onde eles estudam e compartilhado publicamente na rede social Facebook. A partir dos dados obtidos, conclui-se que, ainda que as discussões sobre diversidade sexual tenham ganhado espaço em diferentes cenários, no universo escolar a sexualidade continua como um tema polêmico, considerando a multiplicidade de visões, crenças e valores que compõe esse ambiente. Atravessada por esses embates, permeados por lutas, repressões e resistências advindas da homofobia, um dos grandes desafios da educação brasileira na atualidade é promover o entendimento e respeito à construção das identidades sexuais e de gênero na escola.

Palavras-chave: escola; facebook; homofobia; namoro gay; redes sociais

\footnotetext{
1 Sociólogo e Cientista Político. Doutorando e Mestre em Educação pelo Programa de PósGraduação em Educação da Universidade Federal de Pelotas - PPGE/FAE/UFPel. lucianopereiraluciano@gmail.com
} 


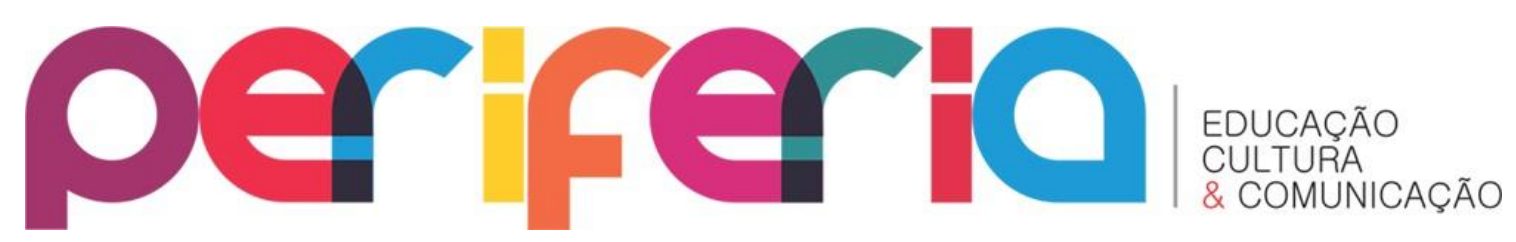

\title{
GAY LOVE DECLARATION IN SCHOOL: COMMENTS ABOUT A POST AT FACEBOOK
}

\begin{abstract}
Overcoming the need for contact, physical and temporal proximity, social networks are places of encounter, exchange, self-exposure. In this sense, the postmodern subject is crossed by the new communication technologies and the mass media that influence its constitution and become privileged locus from where it exposes and legitimizes itself. As a result of globalization, these new practices of social interactions emerge as vehicles for sharing and decentralization of knowledge, while at the same time they risk legitimizing hegemonisms, serving as a vehicle for propagating beliefs and prejudices in the face of cultural diversity, pluralism and the singularities there exposed. The purpose of this article is to discuss the perceptions regarding homosexuality present in contemporary human societies from a brief analysis of the comments generated by the posting of a video recorded on the occasion of the request of courtship done by a teenager to another boy in the schoolyard where they Study and shared publicly on the social network Facebook. Based on the data obtained, it is concluded that, although the discussions on sexual diversity have gained space in different scenarios, in the school universe sexuality continues as a polemic subject, considering the multiplicity of visions, beliefs and values that make up this environment. Crossed by these clashes, permeated by struggles, repressions and resistances arising from homophobia, one of the great challenges of Brazilian education today is to promote understanding and respect for the construction of sexual and gender identities in school.
\end{abstract}

Keywords: school; facebook; homophobia; gay dating; social networks 


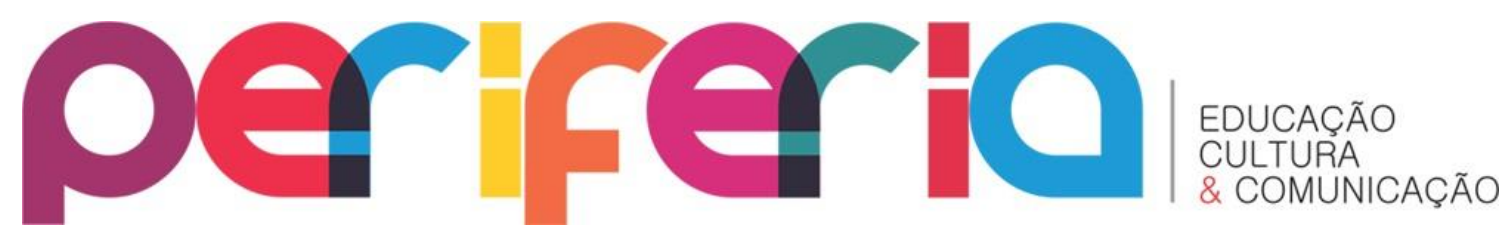

INTRODUÇÃO

"Há mais de três meses, eu conheci uma pessoa muito especial, muito legal, muito divertida, muito inteligente e muito bonita. Essa pessoa me completa. E essa pessoa é esse menino lindo aqui. Há exatamente três meses, nós deixamos de ser 'eu e você', para sermos verdadeiramente 'nós'. E no meio disso, quando um estiver triste, o outro vai ter o apoio pra ficar feliz. E quando um de nós estiver feliz, o outro vai ser o motivo por esse sorriso. E Marcos, você deixa eu fazer você uma pessoa mais feliz possível ?" (OLIVEIRA, Facebook, 2014)

$\mathrm{Na}$ escola, assim como na vida cotidiana, sob as mais variadas situações, as mais distintas, das mais simples às mais complexas, seja na sala de aula ou em qualquer outro ambiente e espaço, são construídos saberes, sujeitos, corpos, identidades, diferenças e hierarquias (CAMARGO \& MARIGUELA, 2007).

O texto em epígrafe é a transcrição das falas de um adolescente em um vídeo gravado por ocasião do pedido de namoro feito por ele a outro garoto no pátio da escola onde eles estudam². Esse vídeo foi compartilhado publicamente na rede social Facebook em 25/06/2014 pelo usuário que nomearemos de B. E. O., em seu perfil na referida rede, sob o título "Pedido de namoro e declaração de amor GAY no Colégio". Em 22/08/2014, a postagem contava com 6.600 curtidas, 12.908 compartilhamentos e 1.119 comentários.

Assim, o objetivo desse artigo é discutir percepções relativas às homossexualidades presentes nas sociedades contemporâneas a partir de uma breve análise dos comentários gerados por essa postagem. Considerando que o fato ocorreu em uma escola, com o intuito de refletir sobre a opinião de estudantes adolescentes sobre o assunto, em 03/07/2014 o vídeo foi postado nas páginas de grupos de alunos no Facebook de duas escolas de Ensino Médio de regiões distintas do país: uma na região sul, localizada no interior do Rio

\footnotetext{
${ }^{2}$ Disponível em: https://www.facebook.com/bruno.drew.bieber/videos/594875210627152/
} 


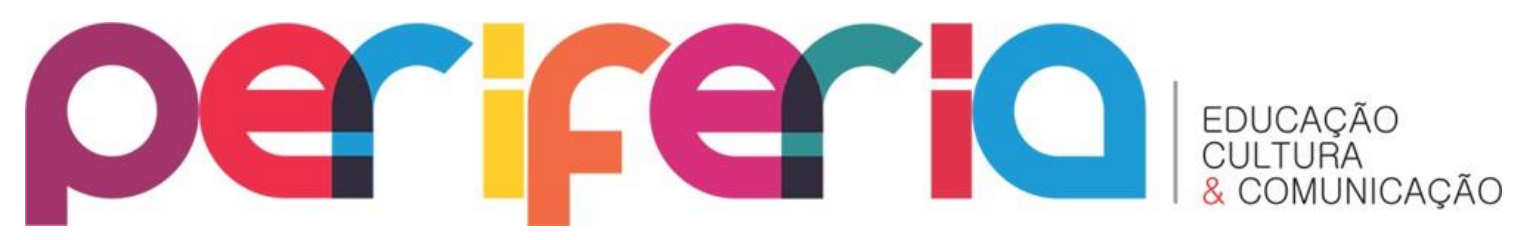

Grande do Sul, na cidade de Pelotas e a outra na região sudeste, localizada na cidade de São Paulo, capital do referido Estado. A escolha dessas cidades se deu por ter o autor atuado como professor nessas escolas tendo assim acesso aos referidos grupos e, ainda, por serem de redes de ensino diferentes - a escola de Pelotas é da rede privada e a de São Paulo da rede pública.

Num primeiro momento, foram analisados os 1119 comentários obtidos a partir da postagem original - desconsiderando os comentários gerados a partir dos compartilhamentos. E, numa segunda etapa, foram analisados os comentários dos grupos de alunos das escolas já mencionadas. Na escola de São Paulo, embora a escola contasse com 960 alunos matriculados no Ensino Médio, obtiveram-se apenas oito comentários e na escola de Pelotas, dos 240 alunos do Ensino Médio, tão somente três comentaram o vídeo. Para efetuar a análise, os comentários foram classificados por sexo, por faixa etária e discursos religiosos com a intenção de extrair os posicionamentos de apoio ou repúdio de acordo com essa classificação. 0 processo de coleta, classificação e análise dos dados compreendeu o período de agosto de 2014 a março de 2015.

\section{BREVE REFERENCIAL TEÓRICO}

A internet, tomada como o resultado mais visível da globalização, surgiu na década de 1970 e se constitui hoje em mais um espaço de sociabilidade e de construção das subjetividades dos indivíduos. Neste contexto, Giddens (2000), ao conceituar globalização, assinala para o fato de que as ações cotidianas de cada sujeito estão entrelaçadas, encadeadas e repercutem em espaços e tempos distantes. A intensificação das relações sociais em escala mundial e as conexões entre as diferentes regiões do globo influenciam os acontecimentos cotidianos locais e vice-versa (GIDDENS 2000, p. 23-24).

Superando a necessidade de contato, proximidade física e temporal, as redes sociais, assim como as comunidades virtuais, são lugares de encontro, 


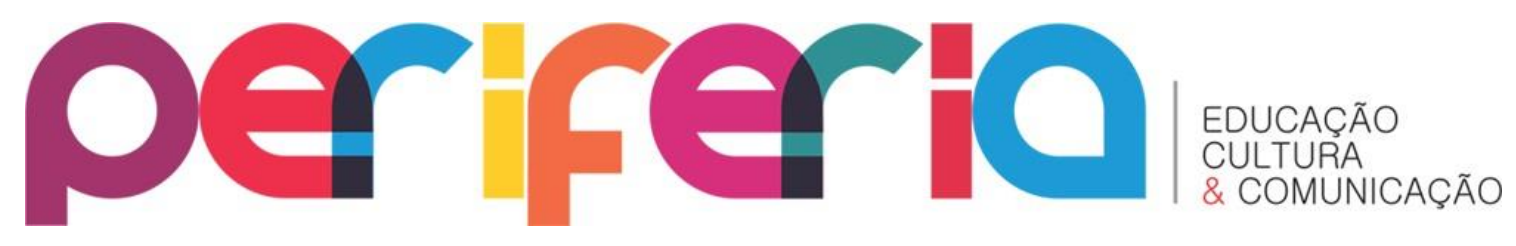

de trocas, de exposição de si. As relações sociais do sujeito pós-moderno tem seu "caráter líquido" demarcado pela reconfiguração das necessidades de proximidade, durabilidade e reciprocidade dos laços sociais contemporâneos. (BAUMAN, 2001, p.126). Assim, na contemporaneidade, redes sociais, sites de encontros, aplicativos para celulares, etc. tornam-se mecanismos para que o sujeito possa desvendar o que concerne ao outro ao passo que, concomitantemente, revela a si mesmo (NEVES, PORTUGAL, 2011, p.17) uma vez que, na medida em que exterioriza a si fazendo-se visível e acessível ao outro, cria a necessidade do olhar do outro no processo de sua própria significação (BRUNO, 2004, p.116).

Nesse sentido, o sujeito pós-moderno é marcado pelo atravessamento onipresente das novas tecnologias da comunicação (NTC) e pelos meios de comunicação de massa que influenciam sua constituição e se tornam nesse processo, lócus privilegiado de onde ele se expõe e se legitima (MEDINA, 2007, p.1). Comunidades Virtuais, Sociedade em Rede, Tribos Urbanas - o surgimento e a popularização dessas e outras expressões atestam para o reconhecimento das rápidas e profundas alterações nas formas como as pessoas se relacionam umas com as outras e que estão em curso na atualidade.

Estas novas práticas de interação social surgem como veículo de compartilhamento e descentralização de saberes, de democratização de conhecimentos, ao passo que, ao mesmo tempo sofrem o risco da legitimação de hegemonismos (COSTA FERNANDEZ, 2013, p.3), servindo como veículo de propagação de crenças e preconceitos diante da diversidade cultural, do pluralismo e das singularidades ali expostas. Assim, as redes sociais criam novos vínculos sociais (LEVY, 1996, p.72), tanto na relação do sujeito com a alteridade e a diversidade cultural, quanto nos processos de subjetivação de si mesmo (GUATTARI, 1992, p.14-15).

Criada em 2004 por Mark Zuckerberg e seus colegas de quarto na Universidade de Harvard, o Facebook é hoje a rede social mais acessada no mundo. Em 2007, essa rede se popularizou no Brasil ao lançar aqui uma versão 


\section{periferio}

em português, chegando em 2014 a 76 milhões de usuários brasileiros, segundo Ribeiro (2014).

Nesse cenário, onde o sujeito vivencia novas formas de relacionar-se com o outro, com o mundo e consigo mesmo, interpelado pelas transformações tecnológicas que o colocam em contato com diferentes culturas, saberes, identidades e posicionamentos, a escola ainda aparece como um espaço disciplinador onde as condutas são moldadas pelo padrão heteronormativo ${ }^{3}$. Um de seus atributos é enquadrar os estudantes nos padrões sociais treinando-os para cumprir regras (FERREIRA E SANTOS, 2014, p.97). Seu papel enquanto instituição vai muito além da transmissão e construção de conhecimentos, funciona como um dispositivo de reprodução dos padrões sociais vigentes. Consolidando e perpetuando valores, a escola constitui e constrói sujeitos, legitimando as relações de poder, as hierarquias e processos de acumulação. Dessa forma, ela atua como um aparelho disciplinador e mantenedor da norma (JUNQUEIRA, 2009a). Portanto, os sujeitos que fogem à norma e diferem-se da maioria social, são socialmente marginalizados.

Pesquisas apontam que, embora a escola devesse constituir-se num espaço de promoção da cidadania, o ambiente escolar se apresenta como hostil, intolerante e violento em relação a lésbicas, gays, bissexuais, travestis, transexuais e transgêneros (LGBTs), configurando-se, por muitas vezes, como espaço de produção e reprodução da homofobia (JUNQUEIRA, 2009a, p.121). Nesse contexto, Junqueira (2009b) destaca ser a escola um ambiente que:

Configura-se um lugar de opressão, discriminação e preconceitos, no qual e em torno do qual existe um preocupante quadro de violência a que estão submetidos milhões de jovens e adultos LGBT - muitos/as dos/as quais

Padrão heteronormativo ou heteronormatividade: conceito criado pelo pesquisador americano Michael Warner em 1993, para descrever a norma que toma a sexualidade heterossexual como norma universal e os discursos que descrevem a situação homossexual como desviante (DINIS, 2011, p.42). 


\section{periferio}

vivem, de maneiras distintas, situações delicadas e vulneradoras de internalização da homofobia, negação, autoculpabilização, autoaversão. $E$ isso se faz com a participação ou omissão da família, da comunidade escolar, da sociedade e do Estado (JUNQUEIRA, 2009b, p.15).

Entretanto, ainda que a escola se constitua como espaço disciplinador, regulador e mantenedor da norma, a juventude da atualidade que também faz parte dela, imbuída nesse processo de "globalização dos sujeitos" e mediada pelas NTC, cria novas formas de vivenciar e expressar as sexualidades, ocupando inclusive o espaço escolar e a ele transpondo, como pode ser observado no vídeo postado no Facebook e descrito a seguir.

\section{A DESCRIÇÃO DO VÍDEO}

Gravado em horário de entrada dos alunos de uma escola pública da cidade de São Paulo/SP, o vídeo retrata uma declaração de amor e pedido de namoro feito por um garoto adolescente a outro. 0 evento ocorre no pátio da escola e conta com a participação de vários estudantes.

0 vídeo inicia-se com vários alunos no pátio, soa o toque do sinal da escola e podem - se ver alunos chegando com mochilas, barulhos, conversas, gritos e assovios típicos desses espaços. Ao fundo vários estudantes estão reunidos, dois deles com violões, alguns com cartazes em folhas sulfite. Quando o pretendente adentra ao pátio, alunos e alunos em coro entoam a canção "Equalize" composta e interpretada pela cantora Pitty. Mais estudantes vão se juntando ao coro.

Então, o declarante caminha até seu pretendente e ao som do coro e embalados por gritos de euforia dos colegas, eles se abraçam e se beijam. 0 declarante então inicia seu discurso: "Há mais de três meses, eu conheci uma pessoa muito especial, muito legal, muito divertida, muito inteligente $e$ muito bonita. Essa pessoa me completa". Colocando o braço ao redor do pescoço do outro rapaz ele fala "E essa pessoa é esse menino lindo aqui". 0 pretendido se emociona e podem-se ouvir os gritos eufóricos dos colegas. 


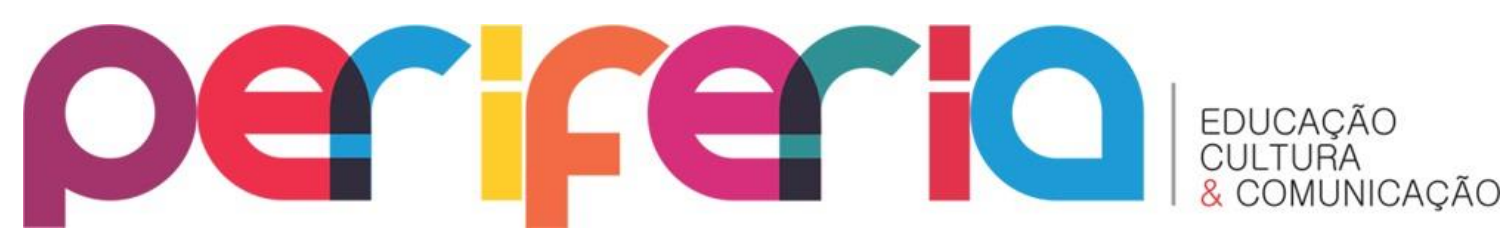

O declarante continua: "Há exatamente três meses, nós deixamos de ser 'eu e você', para sermos verdadeiramente 'nós'". 0 garoto posiciona-se em frente ao rapaz, respira fundo, demonstrando nervosismo e completa " $E$ no meio disso, quando um estiver triste, o outro vai ter o apoio pra ficar feliz". 0 pretendido enxuga as lágrimas e o declarante, com voz emocionada, continua "E quando um de nós estiver feliz, o outro vai ser o motivo por esse sorriso".

De frente para o pretendente, o declarante tira do bolso uma caixinha com alianças, ajoelha-se e conclui "E Marcos, você deixa eu fazer você uma pessoa mais feliz possível?". Aqui, descobrimos que o pretendido se chama Marcos. Ele se emociona e podemos ouvir os gritos eufóricos dos colegas. 0 casal se beija e se abraça, o declarante se ajoelha novamente e coloca a aliança no dedo de Marcos e beija-lhe a mão, ficando novamente de pé. Marcos, então, se ajoelha e coloca a aliança no dedo do declarante, retribuindo-lhe o gesto, e também lhe beija a mão. De pé, ao som dos gritos dos colegas, eles se beijam e se abraçam.

Em seguida, embalados por muitos gritos, o declarante se dirige ao local onde estão os colegas e, ajudado por eles, traz para junto de Marcos uma grande caixa decorada e fechada por um laço de fita. Podemos ouvir os estudantes gritarem "abre, abre, abre...", o que imediatamente o declarante faz, revelando alguns presentes. Marcos, admirado e emocionado, abraça e beija o declarante. 0 burburinho de vozes e gritos aumenta, enquanto 0 casal, visivelmente emocionado, conversa e seca as lágrimas. Podemos notar alguns alunos filmando e fotografando.

Encerrando o vídeo, vemos o depoimento de uma jovem estudante que parabeniza o casal dizendo: "Que o errado é a falta do amor. Errado é o desequilíbrio, é a promiscuidade... $e$ isso, a gente vê nos casais heteros $e$ homossexuais. Errado é a falta do amor. Eles estão de parabéns pela coragem." Ao final a depoente encerra aplaudindo o ato de "coragem" do casal. 


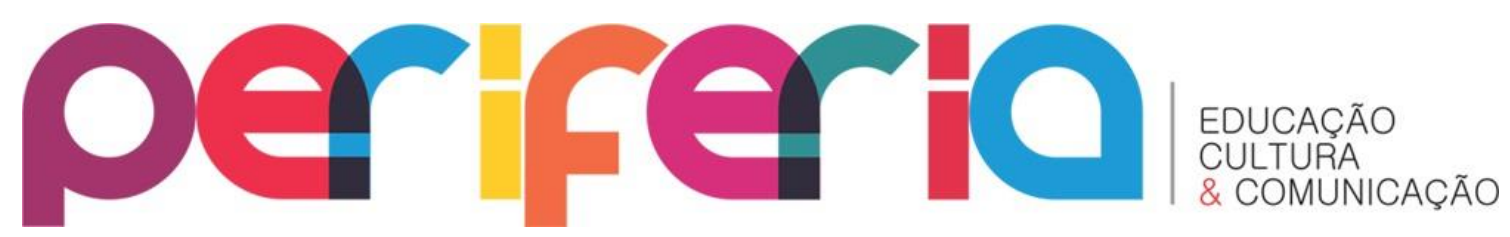

0 vídeo, como dito anteriormente, teve grande repercussão nas redes sociais e o discurso por ele apresentado - entendendo aqui discurso não somente como palavras, mas um conjunto de enunciados compostos por diversas linguagens traduzidas em gestos, sons, emoções, silêncios e postura que indicam intenções (KOHL, 1993, p.35), - causou diferentes reações dos internautas que o assistiram, conforme observamos em seus comentários.

Analisando o vídeo, considerando que relata um fato ocorrido no interior de uma escola e ainda o imenso alcance e visibilidade conquistada na internet, nos remetemos a Foucault (2013)

A troca e a comunicação são figuras positivas que atuam no interior de sistemas complexos de restrição; e sem dúvida não poderiam funcionar sem estes. A forma mais superficial e mais visível desses sistemas de restrição é constituída pelo que se pode agrupar sob o nome de ritual; o ritual define a qualificação que devem possuir os indivíduos que falam (e que, no jogo de um diálogo, da interrogação, da recitação, devem ocupar determinada posição e formular determinado tipo de enunciados); define gestos, os comportamentos, as circunstâncias, e todo o conjunto de signos que deve acompanhar o discurso; fixa enfim, a eficácia suposta ou imposta das palavras, seu efeito sobre aqueles aos quais se dirigem os limites de seu valor de coerção (FOUCAULT, 2013, p.37).

\section{APRESENTAÇÃO E ANÁLISE DOS DADOS}

Diante dessas considerações, apresentamos aqui alguns dados obtidos no presente estudo. Nesta primeira etapa, foram analisados os 1.119 comentários feitos na postagem original. Os comentários feitos nos grupos de estudantes são analisados separadamente na segunda etapa.

- Classificação dos comentários por sexo/gênero ${ }^{4}$ dos usuários da rede social

\footnotetext{
${ }^{4}$ Para a classificação por sexo/gênero foi observado no perfil de cada usuária/o que emitiu comentário como a/o mesma/o se autodeclarava. É importante ressaltar também que a rede social Facebook dá aos seus usuários as opções de: "masculino", "feminino" e
} 


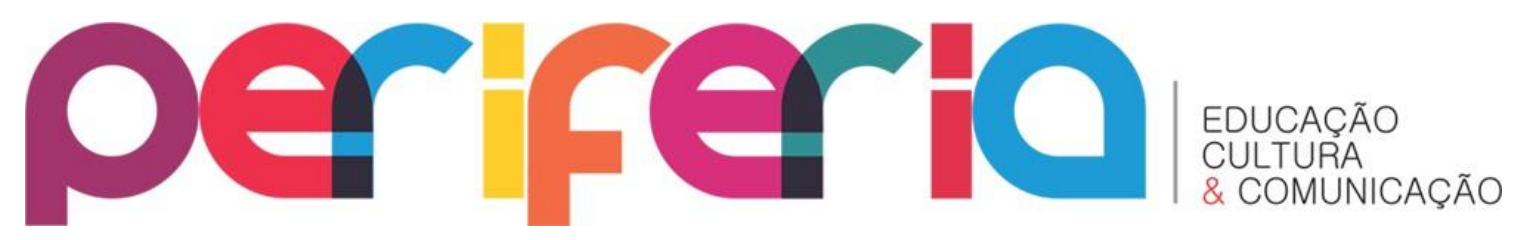

No universo de 1.119 comentários da postagem original, estes foram classificados de acordo com o sexo dos usuários da rede social resultando em $769(69 \%)$ comentários feitos por pessoas do sexo-gênero masculino e 350 (31\%) por pessoas do sexo-gênero feminino. Podemos notar que o número de comentários masculinos é mais que o dobro do número de comentários femininos.

\section{- Classificação por faixa etária ${ }^{5}$}

Em seguida os dados foram classificados por faixa etária atingindo os seguintes números: adolescentes - 657 (59\%); de 21 a 30 anos - 344 (31\%); de 31 a 45 anos - 96 (8\%); acima de 45 anos - 22 (2\%).

Os dados apontam que a maioria dos comentários é de adolescentes e que, na medida em que a faixa etária avança, os comentários se tornam escassos. Esta observação nos remete ao fato de que as transformações ocorridas na sociedade no transcorrer das últimas décadas reconfiguram os sujeitos das novas gerações, (re)-significando conceitos, modificando posturas e posicionamentos diante de questões ainda consideradas tabus, tais como as homossexualidades. Outra reflexão que pode e deve ser feita é de que as gerações mais novas, nascidas e criadas na era da internet, acessam com maior facilidade e frequência às NTC. As gerações mais novas comumente estabelecem interações e relações nos ambiente virtuais. Outro fator ainda a se levar em conta é de que as próprias interações sociais propiciadas pelas NTC favorecem para que as novas gerações tenham maior aceitação e se

\footnotetext{
"personalizado", sendo neste último caso, permitido aos usuárixs determinar em qual gênero se encaixa que não o masculino ou o feminino.

${ }^{5}$ A rede social Facebook só aceita inscrições de usuários a partir de 18 anos de idade, portanto consideraram-se participantes do grupo dos adolescentes as/os usuárias/os que declararam ter entre 18 e 20 anos. Outro método utilizado para a classificação por faixa etária foi observar nos perfis das/dos usuárias/os a idade declarada, postagens e fotografias com o intuito de verificar a qual faixa etária a/o usuária/o pertencia.
} 


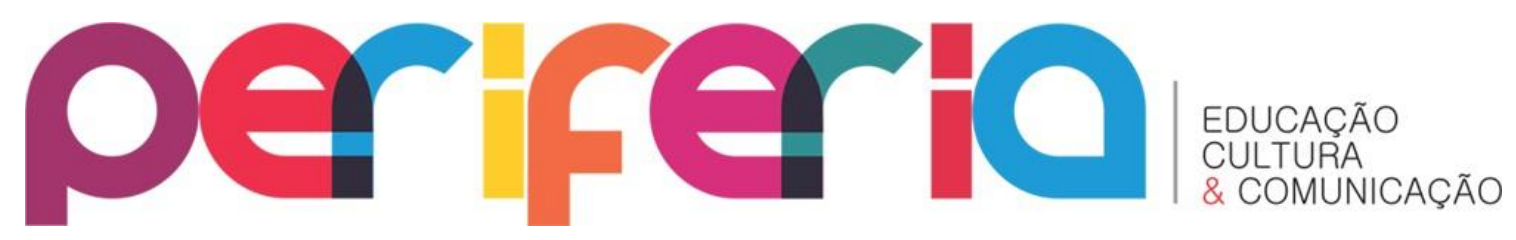

posicionem a favor das diversas formas de expressão do gênero e das sexualidades.

- Classificação por sexo-gênero/ faixa etária

A classificação que segue traz a junção sexo-gênero/faixa etária. Considerando o total de respondentes do sexo-gênero masculino (769), os dados apontaram os seguintes resultados: adolescentes - 437 (57\%); 21 a 30 anos - 263 (34\%); 31 a 45 anos - 56 (7 \%); acima de 45 anos - 13 (2\%).

Quanto ao sexo-gênero feminino (350) os dados aferidos resultaram: adolescentes - 220 (63\%); 21 a 30 anos - 81 (23\%); 31 a 45 anos - 40 (11\%); acima de 45 anos - nove (3\%).

Embora o número absoluto de comentários de pessoas do sexo-gênero masculino seja maior, ao compararmos os dados relativos na relação sexogênero/faixa etária, podemos verificar que adolescentes do sexo feminino (63\%) atingem um percentual maior que adolescentes do sexo masculino (57\%), enquanto na faixa etária entre 21 e 30 anos, os comentários postados por pessoas do sexo masculino (34\%) sobrepõem o percentual de comentários feitos por pessoas do sexo feminino $(23 \%)$.

- Classificação por categorias: apoio, repúdio e indefinidos- marcação de amigos

A partir daí, os comentários foram categorizados por apoio, repúdio ou indefinidos/marcação de amigos, apontando os seguintes resultados: 684 comentários de apoio (61\%), 276 (25\%) de repúdio, enquanto 159 (14\%) comentários se mostraram indefinidos, não se remetendo a nenhum posicionamento ou apenas marcando amigos.

- Classificação por sexo-gênero/categorias: apoio, repúdio e indefinidos marcação de amigos 


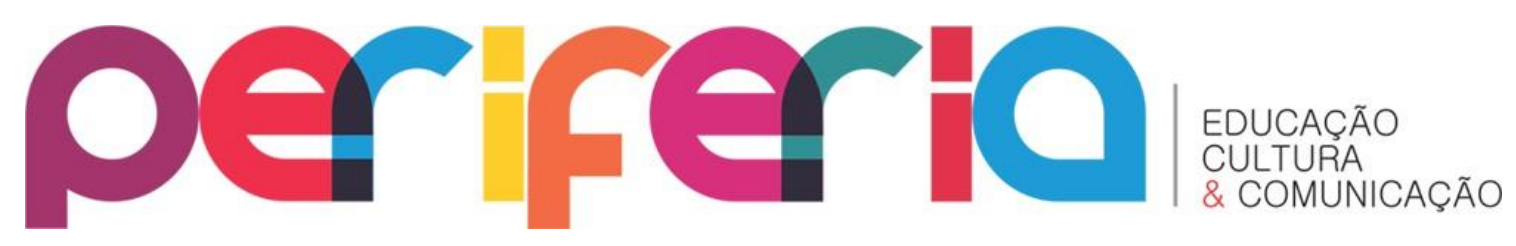

Os comentários femininos se apresentaram da seguinte forma: 288 (82\%) de apoio, 18 (5\%) de repúdio e 44 (13\%) indefinidos/ marcação de amigos.

Dos 769 comentários postados por pessoas do sexo-gênero masculino, 396 (51\%) são de apoio, 258 (34\%) de repúdio enquanto 115 (15\%) são indefinidos- marcação de amigos.

Assim, ao considerarmos os percentuais por sexo-gênero, verificamos que o sexo-gênero feminino se mostra menos preconceituoso que o masculino uma vez que $82 \%$ do total de mulheres que comentaram o vídeo expressaram seu apoio.

- Classificação por sexo-gênero feminino/ faixa etária: apoio, repúdio e indefinidos-marcação de amigos

Com intuito de aferir os resultados considerando a faixa etária e o sexogênero das pessoas que postaram seus comentários, uma nova classificação foi feita. Nesta, obtiveram-se os seguintes números:

Considerando o total de comentários postados pelo sexo-gênero feminino/ adolescentes (220), houve 186 comentários de apoio (85\%); seis de repúdio (3\%); e 28 indefinidos-marcação de amigos (12\%).

$\mathrm{Na}$ faixa de 21 a 30 anos (81), os dados obtidos foram: apoio - 62 (77\%), repúdio - seis (7\%), indefinidos-marcação de amigos -13 (16\%).

A faixa de 31 a 45 anos de idade (40) acusou os seguintes resultados: apoio - 33 (83\%), repúdio - quatro (10\%), indefinidos-marcação de amigos três $(7 \%)$.

Os nove comentários tecidos por mulheres acima de 45 anos resultaram percentualmente em: apoio - sete (78\%), repúdio - dois (22\%).

Ao verificar os dados acima, é possível notar que o apoio configura-se como o maior percentual em todas as faixas etárias do sexo feminino, 


\section{periferio}

sobrepondo em muito as outras categorias, e o repúdio ocupa a menor posição nos percentuais apontados.

- Classificação por sexo-gênero masculino/ faixa etária: apoio, repúdio e indefinidos-marcação de amigos

Do total de 437 comentários postados por adolescentes do sexo masculino, tem-se: apoio - 256 (59\%), repúdio - 129 (30\%), indefinidomarcação de amigos - 52 (12\%).

Do total de 263 comentários masculinos na faixa etária entre 21 e 30 anos, pode-se observar: apoio - 97 (37\%), repúdio - 112 (43\%), indefinidosmarcação de amigos - 54 (21\%).

As 56 postagens realizadas na faixa etária de 31 a 45 anos revela os seguintes percentuais: apoio - 37 (66\%), repúdio -11 (20\%), indefinidosmarcação de amigos - oito (14\%).

Os 13 comentários na faixa etária acima de 45 anos de idade demonstram: apoio - seis (46\%), repúdio - seis (46\%), indefinidos-marcação de amigos - um (8\%).

A observação dos dados relativos a sexo-gênero masculino/- faixa etária mostra que os comentários postados por pessoas com idade entre 31 e 45 anos, considerando a proporcionalidade em relação ao número de postagem nessa faixa, ocupam a primeira posição na categoria apoio. No entanto, cabe ressaltar que os comentários feitos pelos adolescentes excedem em números os de todas as outras faixas etárias e que, na categoria apoio seu percentual chega a 59\%. Em números absolutos, apenas nesse item somam mais da metade de todos os comentários realizados pelo sexo-gênero masculino.

Destaca-se também o fato de que a categoria repúdio aparece de forma mais expressiva nos comentários postados pelo sexo-gênero masculino, ocupando entre a faixa etária de 21 a 30 anos um acentuado número. Esta faixa é a única em que a categoria repúdio supera o apoio. 


\section{per

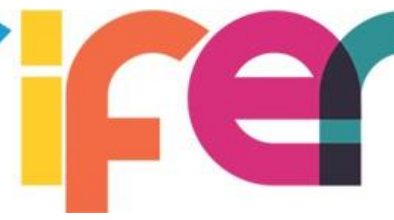

- Classificação por sexo-gênero/ faixa etária/ discursos religiosos

A última classificação foi realizada com o objetivo de mensurar, nas categorias estabelecidas, a presença de discursos religiosos. Foram encontrados, no universo de 1.119 comentários pesquisados, apenas 22 postagens com conteúdo religioso, o que representa apenas $2 \%$ do número total de comentários analisados.

Nos comentários postados pelo sexo-gênero feminino aparecem dois com discursos religiosos que representam $1 \%$ do total de comentários femininos com esse teor na pesquisa, estando estes localizados nas faixas etárias de 21 a 30 anos (um) e acima de 45 anos (um).

Quanto ao sexo masculino, encontramos 20 comentários com discursos religiosos - 3\% do total de comentários analisados. Diferentemente dos dados relativos ao sexo-gênero feminino, os comentários com teor religioso podem ser encontrado em todas as faixas etárias do sexo-gênero masculino, estando assim distribuídos: adolescentes - nove comentários $(45 \%$ do total de comentários religiosos masculinos); 21 a 30 anos - sete (35\%); 31 a 45 anos dois (10\%); acima de 45 anos - dois (10\%).

Os dados referentes aos discursos religiosos demonstram um uso maior do mesmo pelo sexo-gênero masculino, e o maior percentual encontra-se entre os adolescentes. Pode ser observado que tanto no sexo-gênero masculino quanto no feminino, ele pode ser encontrado na faixa etária de 21 a 30 e acima de 45 anos de idade.

- A postagem do vídeo em páginas do Facebook de grupos de alunos de ensino médio

Uma vez observados os dados gerados a partir dos comentários da postagem original do vídeo, e visando analisar as opiniões de alunos do Ensino Médio sobre ele, uma vez que o fato ocorreu numa escola desse nível de ensino, buscou-se quantificar e classificar os comentários gerados a partir das 


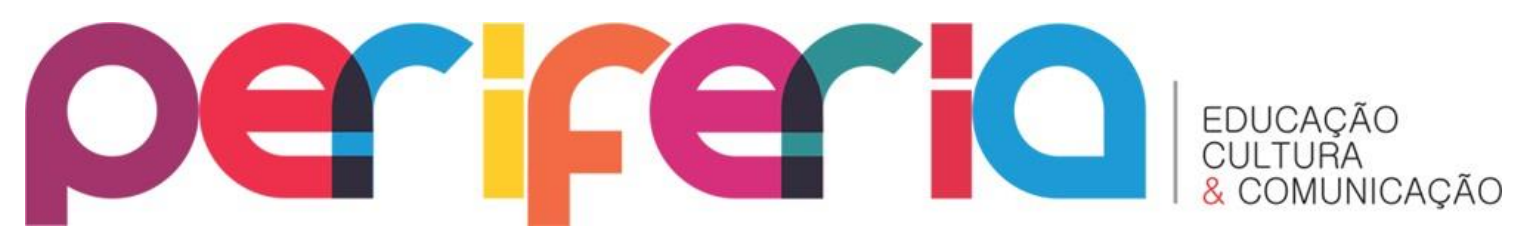

postagens feitas em páginas de redes sociais de grupos de alunos de duas escolas, uma no estado de São Paulo e outra do Rio Grande do Sul

- A escola de São Paulo

A escola está localizada na cidade de São Paulo. É uma escola da rede pública, de Ensino Médio e possui 960 alunos matriculados. Nessa escola obtivemos 30 curtidas, oito comentários e nenhum compartilhamento. Dos oito comentários, temos sete feitos por alunos e um por uma professora. Destes, seis são do sexo feminino sendo cinco de apoio e um sem posicionamento. Quanto aos comentários do sexo masculino, são dois - ambos de apoio. Os comentários não chegam a atingir a marca de $1 \%$ do total de alunos matriculados na escola $(0,008 \%)$.

- A escola do Rio Grande do Sul

A escola está localizada na cidade de Pelotas, no interior do estado. É da rede privada, atende aos níveis fundamental e médio, tendo neste último, 240 alunos matriculados. Nessa escola obtivemos três comentários, sendo um do sexo masculino, sem posicionamento definido e dois do sexo feminino, sendo um contra e outro de apoio. O número de comentários representa $0,001 \%$ do total de alunos matriculados no ensino médio.

\section{REVISITANDO OS DADOS E TECENDO ALGUMAS CONSIDERAÇÕES}

Diante do quadro apresentado pode ser observado que quanto aos dados gerados a partir dos 1.119 comentários da postagem original do vídeo, temos uma maioria de comentários do sexo-gênero masculino. Embora o número de comentários masculinos se sobreponha aos comentários femininos nota-se que $82 \%$ do total de comentários das mulheres expressam apoio. 


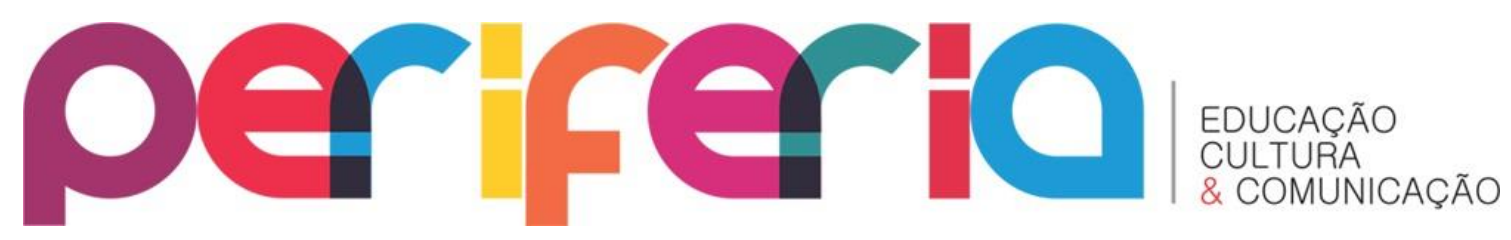

Vale ressaltar que os $51 \%$ (proporcional ao total de homens) de comentários de apoio feitos pelo sexo-gênero masculino, em sua maioria iniciam-se com uma afirmação da heterossexualidade: "sou hetero ...", "não sou gay ...". Se por um lado, tais afirmações da heterossexualidade pode nos indicar que mesmo no ambiente virtual, existe o receio de que a própria sexualidade possa ser questionada pelo simples fato de tecer um comentário de apoio a uma manifestação afetiva entre pessoas do mesmo sexo, como nos aponta Britzman, apud Dinis (2011)

Também faz parte desse complexo mito a ansiedade de que
qualquer pessoa que ofereça representações gays e lésbicas
em termos simpáticos será provavelmente acusada de ser gay
ou de promover uma sexualidade fora da lei. Em ambos os
casos, o conhecimento e as pessoas são considerados
perigosos, predatórios e contagiosos (BRITZMAN, 1996, p.79-80
apud DINIS, 2011, p.43).

Por outro, pode nos assinalar mudanças nas formas de pensar e de agir das masculinidades heterossexuais. Imbricados inclusive pelo grande fluxo de informações proporcionadas pelas NTC, nos é possível pensar que masculinidades possam se declarar heterossexuais e ainda romperem com as normas heteronormativas e apoiarem as homossexualidades.

Quanto à faixa etária, foram as e os adolescentes que mais comentaram, podendo ser notado nessa classificação que o número de comentários diminui à medida que as idades aumentam. A partir dessa constatação, podemos nos remeter às novas configurações sociais, onde na atualidade as pessoas, principalmente os jovens, se sentem mais livres para expressar suas opiniões, sendo as redes sociais um lócus privilegiado para o exercício dessa liberdade. Liberdade esta, conquistada em grande parte pelo ativismo dos movimentos sociais na luta pela conquista e garantia de direitos das minorias. No entanto, é preciso considerar também, como dito anteriormente, que as gerações mais novas têm mais acesso as NTC e estabelecem com maior facilidade interações nos ambientes virtuais e, ao 


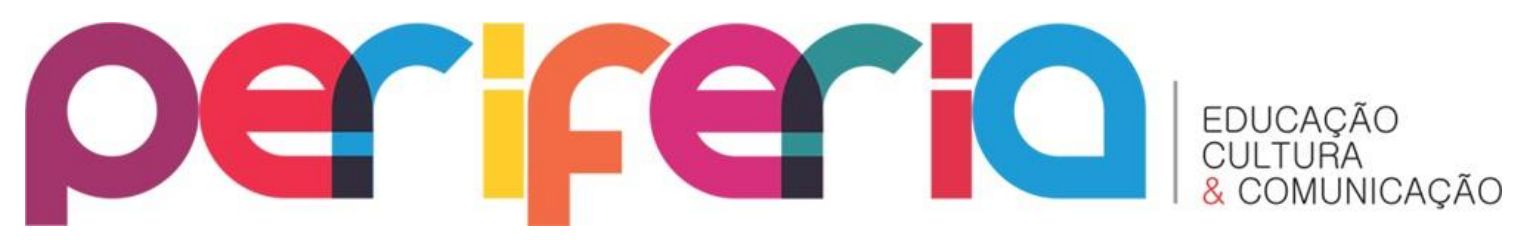

mesmo tempo, as redes sociais, assim como os espaços virtuais, são espaços de "autoproteção" permitindo a criação de personagens fictícios para as manifestações de opiniões que no ambiente dito "real", não seriam feitas.

Enquanto a categoria “apoio" se sobressai em todas as faixas etárias dos comentários femininos, nos comentários masculinos a categoria "repúdio" aparece de forma acentuada entre 21 e 30 anos. Nessa faixa etária são recorrentes comentários sexistas como "tanta mulher no mundo, e o cara vai gostar de homem" e comentários machistas que objetificam a mulher tais como "melhor, sobra mais mulher pra mim".

Quanto aos comentários permeados por discursos religiosos, estes se encontram em sua quase totalidade no sexo masculino, sendo muito expressivos entre adolescentes e na faixa etária entre 21 e 30 anos, o que demonstra que as homossexualidades são alvo de perseguições de correntes de pensamentos conservadoras e de vários segmentos religiosos.

Em relação à postagem do vídeo nas páginas de redes sociais de grupos de alunos de ensino médio, pode ser constatada a ínfima participação dos mesmos na tessitura de comentários. Isso pode ser atribuído ao fato de que, por se conhecerem e frequentarem os mesmos espaços, alunos e alunas se sintam com a liberdade de expressão reduzida, pela possibilidade de anonimato ser anulada. Ao se manifestarem contra, podem ser rotulados como homofóbicos; ao se mostrarem a favor, temem ser rotulados como gays por associação a essa identidade. Essa participação pequena expressa a diferença entre a escola, considerada um "ambiente fechado" e as redes sociais, consideradas um “ambiente aberto".

Embora o vídeo seja fruto de um fato ocorrido na escola e que ganhou visibilidade nas redes sociais, valendo ressaltar aqui que o mesmo, no período analisado, ultrapassou as barreiras geopolíticas e culturais, sendo compartilhado por internautas do Egito, Iraque, Argentina, Colômbia, Estados Unidos da América, México, Espanha, Venezuela, Panamá, Cuba, Camboja, Paraguai, Uruguai, Portugal, França, Inglaterra, Alemanha e Itália, ao retornar 


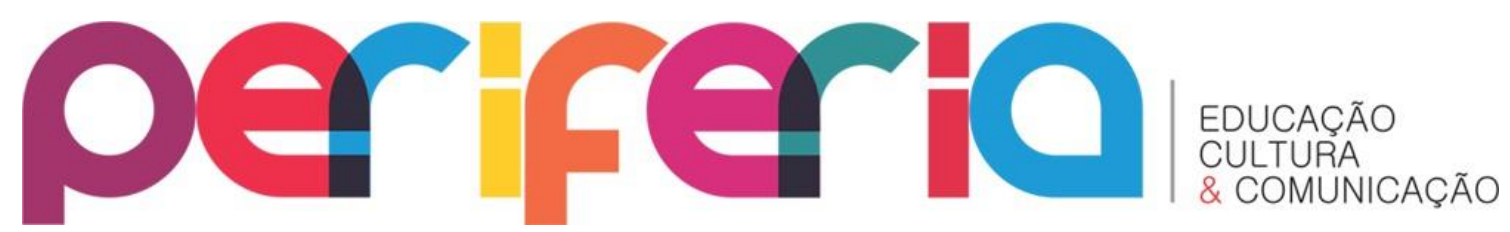

à escola, por ser um "ambiente fechado" onde as pessoas podem ser identificadas, obteve inexpressiva repercussão.

Compreendendo o conceito de dispositivo tal qual nos elucida Foucault

um conjunto decididamente heterogêneo que engloba discursos, instituições, organizações arquitetônicas, decisões regulamentares, leis, medidas administrativas, enunciados científicos, proposições filosóficas, morais, filantrópicas. Em suma, o dito e o não dito são os elementos do dispositivo. 0 dispositivo é a rede que se pode tecer entre estes elementos (FOUCAULT, 2000, p. 244).

E conforme anuncia Bourdieu (1992, p.52), a escola evidencia-se como uma instituição que além de transmitir e construir conhecimentos opera como um dispositivo de reprodução dos padrões sociais vigentes, e dessa forma consolida e perpetua valores e, constitui e constrói os sujeitos, legitima as relações de poder, hierarquias e processos de acumulação. Atua como um aparelho disciplinador e mantenedor da norma (JUNQUEIRA, 2009a, p.120). No entanto, a escola não cabe ser vista como espaço estático, dado o caráter cultural que a institui. Ela [escola] tanto rejeita, quanto produz e/ou compartilha significados, uma vez que ali permeiam conflitos, tensões e disputas e se estabelecem relações de poder (MOREIRA E CANDAU, 2003). Nessa perspectiva, configura-se em um ambiente em movimento, onde se estabelecem embates entre políticas, discursos e práticas.

Podemos concluir que, ainda que as discussões sobre diversidade sexual tenham ganhado espaço em diferentes cenários como política, educação, movimentos sociais e mídias, no universo escolar a sexualidade continua como um tema polêmico, considerando a multiplicidade de visões, crenças e valores que compõe esse ambiente, tanto é que em 2015 a bancada fundamentalista no Congresso Nacional excluiu do Plano Nacional de Educação (PNE) as discussões sobre gênero e orientação sexual nas escolas. Como reflexo desta ação, os temas também foram excluídos dos Planos Estaduais em oito estados 


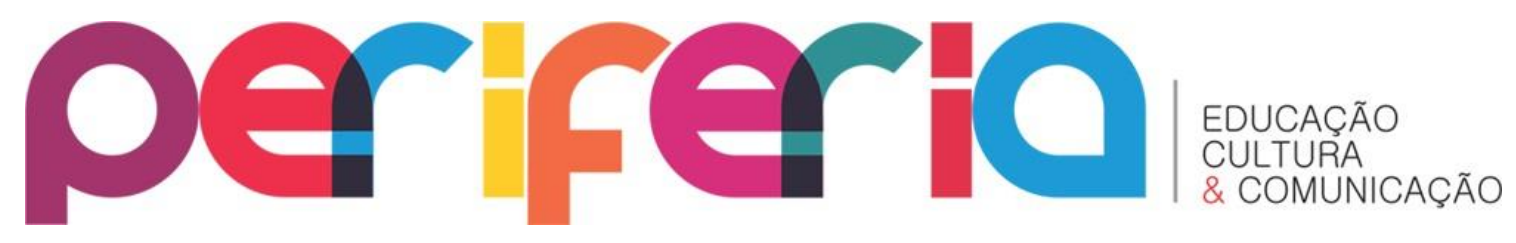

e dos Planos Municipais em grande parte dos municípios brasileiros (CNTE, 2015).

Ao tempo em que se apresenta como um tema que incentiva e provoca o debate, as homossexualidades continuam sendo alvo de perseguições pautadas em correntes de pensamentos conservadoras e segmentos religiosos. Nas escolas, assim como em outros espaços, o tema é permeado por tabus e preconceitos e quando se trata das homossexualidades, certamente a questão se torna mais delicada diante da sociedade heteronormativa em que vivemos.

Ainda que sejam grandes as dificuldades é possível perceber alguns avanços alcançados nos últimos anos, pois a escola é também um espaço de lutas e resistências. Ensejamos que não se despreze o caráter potencializador das mobilizações organizadas pelo corpo discente. Apesar do embate político e do cerceamento das discussões sobre diversidade sexual na escola e, embora a inclusão de temas como orientação sexual e identidade de gênero nas grades curriculares venha sendo combatida por correntes conservadoras, como destacamos nesse artigo as/os estudantes resistem e criam estratégias de experienciar e viver suas sexualidades, colocando de formas alternativas essas discussões na pauta escolar.

Atravessada por esses embates, permeados por lutas, repressões e resistências advindas da homofobia, a educação brasileira tem como um de seus grandes desafios na atualidade promover o entendimento e respeito à construção das identidades sexuais e de gênero na escola.

\section{REFERÊNCIAS}

BAUMAN, Z. Modernidade líquida. Rio de Janeiro: Ed. Jorge Zahar, 2001. BORDIEU, P. A reprodução. Rio de Janeiro: Francisco Alves, 1992.

BRITZMAN, D. 0 que é esta coisa chamada amor: identidade homossexual, educação e currículo. Educação \& Realidade, Porto Alegre, v. 21, n. 1, p. 71 96, jan/ jun 1996. 


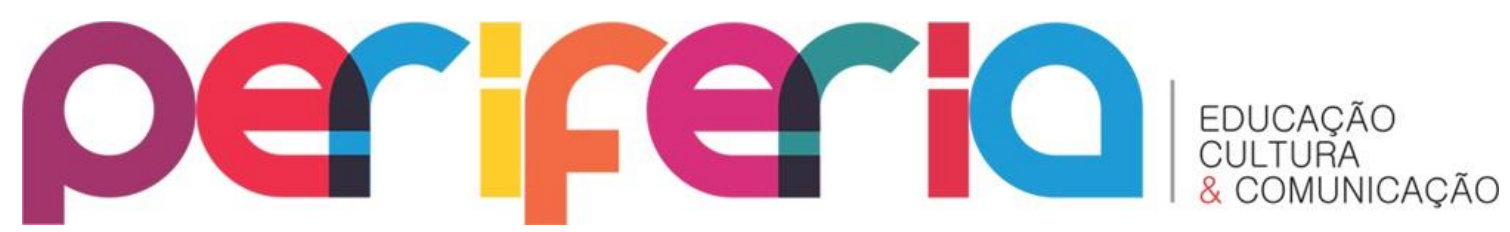

BRUNO, F. G. Máquinas de ver, modos de ser: visibilidade e subjetividade nas novas tecnologias de informação e de comunicação. Revista FAMECOS: mídia, cultura e tecnologia, n. 24, p. 110-124. 2004.

CAMARGO, A. M. F. de; MARIGUELLA, M. Cotidiano escolar. Piracicaba: Jacintha,2007.

CNTE (Confederação Nacional dos Trabalhadores em Educação). Gênero e diversidade sexual na escola: a CNTE apoia os movimentos sociais. Revista Retratos da Escola, Brasília, v.9, n.16, p. 187-194, jan/jun. 2015. Disponível em <http://www.esforce.org.br/index. php/semestral/article/view/493 >. Acesso em: 01 out. 2017.

COSTA FERNANDEZ, E. Impacto das Novas Tecnologias da Comunicação (NTC) na subjetivação e socialização de adolescentes do Recife Cadernos Camilliani, v. 14 n.1, Cachoeiro de Itapemirim, 2013.

DINIS, N. F. Homofobia e educação: quando a omissão também é signo de violência. Educar em Revista, Curitiba, Brasil. n.39. p.39-50, jan./abr. 2011. Editora UFPR.

FERREIRA, M. O. V.; SANTOS, L. P. dos. Diversidade sexual e docência na produção do grupo de trabalho 23 da ANPEd (2004/2011). Revista de Educação PUC - Campinas, Campinas, v.19, n.3, p.195-204, set/ dez. 2014.

FOUCAULT, M. A ordem do discurso. 23a Ed. São Paulo, Edições Loyola. (2013)

GIDDENS, A. O mundo na era da globalização. Lisboa: Presença, 2000.

GUATTARI, F. Caosmose: um novo paradigma estético. Tradução de Ana Lúcia de Oliveira e Lúcia Cláudia Leão. Rio de Janeiro: Ed. 34, 1992.

HELLER, A. O cotidiano e a história. 4. ed. Rio de Janeiro: Paz e Terra, 1992.

JUNQUEIRA, R. D. Diversidade sexual e homofobia: a escola tem tudo a ver com isso. In XAVIER FILHA, C. (org.). Educação para a sexualidade, para a equidade de gênero e para a diversidade sexual. Campo Grande: UFMS, 2009a, p. 111-142.

Homofobia nas escolas: um problema de todos. In: JUNQUEIRA, R.D. (org). Diversidade sexual na educação: problematizações sobre homofobia nas escolas. Brasília: MEC/UNESCO, 2009b, p.13-51.

KOHL de OLIVEIRA, M. Vygotsky - aprendizado e desenvolvimento um processo sócio-histórico. São Paulo: Scipione, 1993. 


\section{periferio}

LÉVY, P. O que é o virtual. Tradução de Paulo Neves. São Paulo: Editora 34, 1996.

MEDINA, C. B. Corpo, Subjetividade e Tecnologias da Comunicação: 0 'Cuidado de Si' na Atualidade. Trabalho apresentado no XIV Encontro Nacional da Associação Brasileira de Psicologia Social (ABRAPSO), UERJ -RJ, 31 out. - 3 nov. 2007.

MOREIRA, A. F.; CANDAU, V. M. Educação escolar e cultura (s): construindo caminhos. Revista Brasileira de Educação, São Paulo: mai/jun/jul/ago, n²3, 2003.

NEVES, C., PORTUGAL, F. T. A dimensão pública da subjetividade em tempos de Orkut. Psicologia \& Sociedade, v. 23, n.1, p. 15-23. 2011.

OLIVEIRA, B.O.; "Pedido de namoro e declaração de amor GAY no Colégio". Vídeo. Disponível em <https://www.facebook.com/video.php?v=594875210627152>. Acesso em: 25 jun. 2014.

RIBEIRO, M. Facebook, 10 anos e mais de um bilhão de usuários. Revista Eletrônica Sul 21. Fev/ 2014. Disponível em:

<http://www.sul21.com.br/jornal/facebook-10-anos-e-mais-de-1-bilhao-deusuarios/>. Acesso em 25 ago. 2014.

TEDESCO, J. Paradigmas do cotidiano. 2. ed. Santa Cruz do Sul: EDUNISC, 2003. 